\title{
Affective theory of the mind and suicide in women with borderline personality disorder and schizophrenia: a comparative study
}

Moustafa Mohamed Mohamed Abdo ${ }^{*^{*}}$ (D) Ahmed Saad Mohamed ${ }^{2}$, Marwa Abd Elmeguid Hammed², Reem Elsayed Hashem² and Zeinab Mohamed El Nagar ${ }^{3}$

\begin{abstract}
Background: Theory of mind (ToM) is one of the essential components of social cognition. Affective ToM enables us to interpret other's feelings and behaviors. Borderline personality disorder (BPD) and schizophrenia are two distinct mental disorders, yet they have a mutual deficit in interpreting emotions, thoughts, and intentions which may lead to a higher incidence of suicidality. Studies that involved social cognition, particularly ToM in schizophrenia, or BPD have controversial results. Therefore, this study aimed at comparing affective ToM functioning in female patients with BPD, schizophrenia, and healthy controls. In addition, identifying the possible impact and any correlation exists between the affective ToM and liability for suicide in those patients. Sixty individuals were recruited from the Institute of Psychiatry, Ain Shams University, Cairo, Egypt, and assigned into 3 groups where group A involved 20 BPD patients, group B involved 20 schizophrenic patients, and group C were healthy persons as a control. Assessment of affective ToM was done using Reading the Mind in the Eyes Test (RMET), and probability of suicide was measured using Suicide Probability Scale (SPS).
\end{abstract}

Results: Regarding ToM, the three groups were assessed using RMET and the results revealed a significantly higher mean score (hypermentalization) in BPD patients than both schizophrenic patients and controls. While schizophrenic patients had significantly lower mean scores than the control group (hypomentalization). As well, BPD patients had a significantly higher suicide probability total score than Schizophrenic patients and in all subdomains except for the hostility subdomain that was significantly higher in schizophrenic patients. Interestingly, in BPD, the suicide probability total score was positively correlated with RMET.

Conclusions: BPD patients have enhanced affective ToM and hypermentalization that is significantly associated with increased suicide probability in those patients, while in schizophrenia, hypomentalization could not be linked to increased suicide probability. Rehabilitation and proper management of ToM abnormalities might be a crucial tool in suicide prevention in mental illnesses, particularly, BPD.

Keywords: Theory of mind, Borderline personality disorder, Schizophrenia, Suicide

\footnotetext{
* Correspondence: Moustafa.abdo.asu@gmail.com

${ }^{1}$ Psychiatry Department, Psychological Medicine Hospital, Neuropsychiatry

M.B.B.CH, Arab Board of Psychiatry, Cairo 11843, Egypt

Full list of author information is available at the end of the article
}

\section{Springer Open}

(- The Author(s). 2021 Open Access This article is licensed under a Creative Commons Attribution 4.0 International License, which permits use, sharing, adaptation, distribution and reproduction in any medium or format, as long as you give appropriate credit to the original author(s) and the source, provide a link to the Creative Commons licence, and indicate if changes were made. The images or other third party material in this article are included in the article's Creative Commons licence, unless indicated otherwise in a credit line to the material. If material is not included in the article's Creative Commons licence and your intended use is not permitted by statutory regulation or exceeds the permitted use, you will need to obtain permission directly from the copyright holder. To view a copy of this licence, visit http://creativecommons.org/licenses/by/4.0/. 


\section{Background}

The term "social cognition" can be defined as social interactions that include the perception and interpretation of the intentions, dispositions, and behaviors of others with the generation of a response to these behaviors. Social cognition consists of subdomains, namely theory of mind, social perception, social knowledge, attributional bias, and emotion processing. Thus, social cognition is vital for successful and adaptive behavior in social life [1]. For a long time, studies of social behavior and genetics were parallel spectrums of research that rarely interfaced. Surprisingly, recent studies identify a network of brain structures 'social brain' as an intermediate step between these two fields and genes are now considered as possible factors in daily social interaction [2].

The Theory of Mind (ToM) reflects the ability to infer mental states such as beliefs, desires, intentions, imagination, and emotions that cause actions [3]. Poor performance in ToM tasks has been reported to be associated with social and behavioral deviations. Deficits in ToM exhibit a cornerstone in the etiology of many psychiatric symptoms and have been used to predict social competence [4]. ToM deficits have been reported in many psychological and neurological disorders, such as the ToM deficit in schizophrenia and its effect on social behavior [1], and personality disorders such as borderline personality disorder [5-7]. An additional distinction can be made between components of ToM: one component is involved in understanding others' intentions and beliefs (cognitive, 'cold' ToM or cognitive empathy), whereas the other one processes other people's feelings and emotions (affective, 'hot' ToM or affective empathy) [8].

Schizophrenia is characterized by changes in language, thinking, mood, social activity, affection, and volition [9]. Schizophrenic patients usually exhibit impaired social cognition interpreted as difficulties in identifying emotions and feelings. Studies have pointed the characteristic symptoms in schizophrenia to social cognition rather than neurocognition [1].

Borderline personality disorder (BPD) is characterized by interpersonal and affective instability, impulsivity, and identity problems [10]. The impairment in interpersonal appraisals comprises the core in severe interpersonal instability seen in BPD, e.g., expectations of abandonment and extremely positive and negative views of others which may initiate suicidality and self-injurious behaviors [11]. Nevertheless, the change in ToM has been linked to the disturbance that occurs in individuals diagnosed with BPD when compared to healthy individuals [12]. A controversy regarding social cognition effect and level has been detected. Some studies have found a decrease or no change in ToM in BPD patients [6, $13,14]$, while other studies have found increased performance compared to healthy controls on ToM [4,
6]. The significant role and involvement of ToM in BPD and schizophrenia urge further investigation of that crucial tool.

In the current study, we hypothesized that patients with borderline personality disorder and patients with schizophrenia have the theory of mind abnormalities compared to healthy controls. This could be the key to interpersonal appraisal deficits which underly social interaction difficulties. Therefore, we expect that theory of mind abnormalities may be linked to suicidal probability in those patients.

The rationale of our study is that understanding the type of social cognition dysfunction in BPD and schizophrenia patients and the possible association between ToM deficits and suicide would help in early prediction of who is at risk for suicide, benefit from including new interventions targeted at improving social cognition and functioning which could decrease suicidal risk and improve prognosis and overall quality of life of those patients.

\section{Methods}

Study design and participants

A cross-sectional, comparative study was approved by the ethics committee of the Institute of Psychiatry, Ain Shams University. A convenient sample of patients diagnosed with BPD and schizophrenia was selected from the outpatient clinics of Ain Shams University, Psychiatry Department, Cairo, Egypt, which was held during the period between October 2018 and January 2021. The Institute of Psychiatry is located in Eastern Cairo and serves a catchments area of about the third of Greater Cairo. It serves both urban and rural areas.

The study included a statistically significant number of 60 individuals, and they were divided into three groups, each included 20 patients. Group (A): patients that were diagnosed with BPD, group (B): patients that were diagnosed with schizophrenia, and group (C): healthy controls.

\section{Inclusion criteria}

Patients included in the group (A) were (1) diagnosed using the Structured Clinical Interview for DSM-IV Axis II Disorders (SCID-II), for assessment and diagnosis of personality disorders; (2) age: 18-45 years; and (3) sex: females. All group (A) patients were not medicated. Patients included in the group (B) were (1) diagnosed using the (SCID-I); (2) patients in full remission (a period after a previous episode during which no disorder-specific symptoms are present), all were on the secondgeneration antipsychotics; (3) age: 18-45 years; and (4) sex: females. The inclusion criteria for group (C) were (1) healthy subjects that did not have a mental illness or 
personality disorders, based on the SCID-I and II, and (2) matching the patient's groups in age and sex.

Gender was limited to females only as to our knowledge females are more likely to attempt suicide than males are; however, males are more likely to succeed to complete suicide.

\section{Exclusion criteria}

Individuals were excluded from the three studied groups if (1) they were presented with any other psychiatric comorbidity (any patient with additional current or past DSM-IV diagnosis on Axis I/II were not recruited); (2) they were presented with mental retardation or developmental disability; (3) they were presented with a neurological disorder or uncontrolled medical condition as indicated by the clinical history, physical examination, laboratory, or radiological findings; (4) they cannot read or write; and (4) they refused to sign the informed consent before enrolment in the study.

\section{Study tools}

All subjects were assessed by using the following tools.

A detailed history data sheet (Ain Shams Psychiatry Clinical Interview) was used to record demographic information, clinical history of the participants, and concurrent medical conditions.

\section{The Structured Clinical Interview for DSM-IV Axis I Disorders (SCID-I) [15]}

SCID-I is a structured diagnostic interview designed for use by mental health professionals. It assesses 33 of the more commonly occurring psychiatric disorders described in the fourth edition of the DSM-IV of the APA. Furtherly, the Arabic version of SCID I was also previously validated and used in our study accordingly [16].

\section{The Structured Clinical Interview for DSM-IV Axis II Disorders (SCID-II) [17]}

SCID-II is a valid and reliable is a tool that has been conducted as a clinical interview to mainly assess the dimensions and categories of the DSM-IV personality disorders. The Arabic version of SCID II was previously validated and used accordingly in our study [18].

\section{The Reading the Mind in the Eyes Test (RMET) (mental state} decoding) (eyes task) [19]

This test was genuinely reported for properly assessing affective ToM. A total of 36 pictures were presented for both genders, exhibiting the eye region of the faces. It should be noted that four emotion-descriptive words usually surround each one of the 36 pictures, and subjects were then asked to describe and interpret these pictures. The Arabic version of RMET was previously validated and used accordingly in the present study [20].

\section{The Suicide Probability Scale (SPS) [21]}

This test has been adequately validated by previous investigations for assessment of the risk of suicide among adolescents and adult populations that exceed 14 years of age. The test is composed of a total of 36 items that assess suicide ideation, negative personal evaluation, hopelessness, and hostility, as reported by the tested individuals to obtain a proper diagnosis in the most comprehensive and fair method. Each item of the test is graded by a 4-point scale ranging between 1 and 4, referring to "little or none" to "all or most" of the time. Three summary scores were furtherly reported, including the SPS, a total weighted score, and a normalized $T$ score. The Arabic version was validated and used accordingly in the present study [22].

\section{Statistical analysis}

For adequate assessment and evaluation of our outcomes, chi-square test, means (standard deviations), independent $t$ test, analysis of variance (ANOVA), and Tukey's test for analyzing the included data were involved, for which the Statistical Package for Social Science (SPSS) V20 was used. A $P$ value $<0.05$ is considered significant.

\section{Results}

\section{Socio-demographic and clinical data}

The means of the age of both groups of BPD and schizophrenia patients were $27.100 \pm 4.909$ years and $30.150 \pm$ 5.696 years, respectively, and that of controls was 30.250 \pm 5.428 years, all included participants were females. The studied groups were matched based on age, marital status, educational level, and medical comorbidities with no significant differences among the 3 groups.

However, the schizophrenia group had more unemployed patients and more family history of psychiatric illness compared to both BPD and controls, while BPD had more history of separated parents, as shown in Table 1.

\section{Comparative results between the three groups}

RMET among the three groups disclosed that BPD patients had significantly higher mean scores than both schizophrenic patients and healthy controls, with a $P$ value $<0.001$. While schizophrenic patients had a significantly lower mean score than the control group with a $P$ value $<0.001$, as shown in Table 2 and Fig. 1 . Meanwhile, on the suicide scale, the SPS revealed that both BPD and schizophrenic patients had a significantly higher suicide probability compared to healthy controls in both total score and its subdomains. Nonetheless, BPD patients showed a significantly higher suicide probability than schizophrenic patients except hostility that was 
Table 1 Sociodemographic and clinical data of the studied groups.

\begin{tabular}{|c|c|c|c|c|c|c|c|c|}
\hline \multirow[t]{2}{*}{ Variables } & & \multicolumn{2}{|l|}{ BPD } & \multicolumn{2}{|c|}{ Schizophrenia } & \multicolumn{2}{|c|}{ Control } & \multirow{2}{*}{$\begin{array}{l}P \\
\text { value }\end{array}$} \\
\hline & & $N$ & $\%$ & $N$ & $\%$ & $N$ & $\%$ & \\
\hline \multirow[t]{2}{*}{ Age } & Range & 20 & 38 & 21 & 46 & 21 & 45 & 0.116 \\
\hline & Mean \pm SD & 27.1 & 4.909 & 30.15 & 5.696 & 30.25 & 5.428 & \\
\hline \multirow[t]{3}{*}{ Marital status } & Single & 16 & 80 & 12 & 60 & 12 & 60 & 0.352 \\
\hline & Married & 2 & 10 & 7 & 35 & 7 & 35 & \\
\hline & Divorced & 2 & 10 & 1 & 5 & 1 & 5 & \\
\hline \multirow[t]{3}{*}{ Educational level } & Technical & 5 & 25 & 6 & 30 & 4 & 20 & 0.925 \\
\hline & University & 11 & 55 & 11 & 55 & 11 & 55 & \\
\hline & Postgraduate & 4 & 20 & 3 & 15 & 5 & 25 & \\
\hline \multirow[t]{2}{*}{ Work } & Unemployed & 7 & 35 & 16 & 80 & 6 & 30 & $0.002^{*}$ \\
\hline & Employed & 13 & 65 & 4 & 20 & 14 & 70 & \\
\hline \multirow[t]{2}{*}{ Parental separation } & Non separated & 12 & 60 & 14 & 70 & 19 & 95 & $0.031^{*}$ \\
\hline & Separated & 8 & 40 & 6 & 30 & 1 & 5 & \\
\hline \multirow[t]{2}{*}{ Medical comorbidities } & Positive & 8 & 40 & 6 & 30 & 1 & 5 & 0.153 \\
\hline & Negative & 18 & 90 & 15 & 75 & 19 & 95 & \\
\hline \multirow[t]{2}{*}{ FH of psychiatric illness } & Negative & 11 & 55 & 7 & 35 & 17 & 85 & $0.005^{*}$ \\
\hline & Positive & 9 & 45 & 13 & 65 & 3 & 15 & \\
\hline \multirow[t]{2}{*}{ DOI } & Range & 1 & 20 & 1 & 20 & - & $0.281^{* * *}$ & \\
\hline & Mean \pm SD & 6.1 & 5.077 & 7.85 & 5.05 & - & & \\
\hline \multirow[t]{2}{*}{ Number of the previous admissions } & Range & 1 & 7 & 1 & 7 & - & $0.799^{* * *}$ & \\
\hline & Mean \pm SD & 2.857 & 2.854 & 2.6 & 2.062 & - & & \\
\hline \multirow[t]{2}{*}{ Medical comorbidities } & Positive & 8 & 40 & 6 & 30 & 1 & 5 & 0.153 \\
\hline & Negative & 18 & 90 & 15 & 75 & 19 & 95 & \\
\hline \multirow[t]{2}{*}{ FH of psychiatric illness } & Negative & 11 & 55 & 7 & 35 & 17 & 85 & $0.005^{*}$ \\
\hline & Positive & 9 & 45 & 13 & 65 & 3 & 15 & \\
\hline
\end{tabular}

$P$ value $>0.05$ : Significant, $S D$ standard deviation. Chi-square test was used for comparison; ${ }^{*}$ statistically significant, ${ }^{* *}$ comparison was done by ANOVA, ${ }^{* * *}$ comparison was done by $t$ test, $B P D$ borderline personality disorder, DOI duration of illness, FH family history

significantly higher in schizophrenic patients, as shown in Table 3 and Fig. 2.

\section{REMT and suicide in patients with BPD}

All suicide subdomains and suicide probability total scores had a significant positive correlation with RMET, except negative self-evaluation. Hopelessness, hostility, and suicidal ideation were moderately correlated with a $P$ value of $0.008,0.001$, and 0.003 , respectively, and suicide probability was strongly correlated with a $P$ value $<$ 0.001. Consequently, indicating that boosted score of
ToM in BPD is associated with significantly higher suicide probability, as shown in Table 4 .

\section{REMT and suicide in patients with schizophrenia}

Suicidality in schizophrenia was negatively correlated with RMET score. Although the insignificant correlation was seen in all SPS subdomains and total score with RMET, hopelessness was found inversely proportional with significant correlation ( $P$ value 0.017$)$, as shown in Table 5.

Table 2 Comparison of RMET mean score between the studied groups

\begin{tabular}{|c|c|c|c|c|c|c|c|c|c|c|c|c|c|c|}
\hline \multirow{3}{*}{$\begin{array}{l}\text { RMET } \\
\text { Range }\end{array}$} & \multicolumn{9}{|l|}{ Groups } & \multicolumn{2}{|l|}{ ANOVA } & \multicolumn{3}{|c|}{ Tukey's test } \\
\hline & \multicolumn{3}{|l|}{$\overline{\mathrm{BPD}}$} & \multicolumn{3}{|c|}{ Schizophrenia } & \multicolumn{3}{|l|}{ Control } & \multirow{2}{*}{$\begin{array}{l}\boldsymbol{F} \\
151.477\end{array}$} & \multirow{2}{*}{$\begin{array}{l}\boldsymbol{P} \text { value } \\
0.001^{*}\end{array}$} & \multirow{2}{*}{$\begin{array}{l}\text { B\&S } \\
<0.001^{*}\end{array}$} & \multirow{2}{*}{$\begin{array}{l}\text { B\&C } \\
<0.001^{*}\end{array}$} & \multirow{2}{*}{$\frac{\text { S\&C }}{<0.001^{*}}$} \\
\hline & 25 & - & 33 & 10 & - & 21 & 19 & - & 26 & & & & & \\
\hline Mean \pm SD & 28.750 & \pm & 2.124 & 15.100 & \pm & 3.024 & 22.200 & \pm & 2.191 & & & & & \\
\hline
\end{tabular}

$P$ value $>0.05$ : significant, ${ }^{*}$ statistically significant, $S D$ standard deviation, RMET Reading the Mind in the Eye Test, $B$ borderline, $C$ controls, and $S$ schizophrenia 


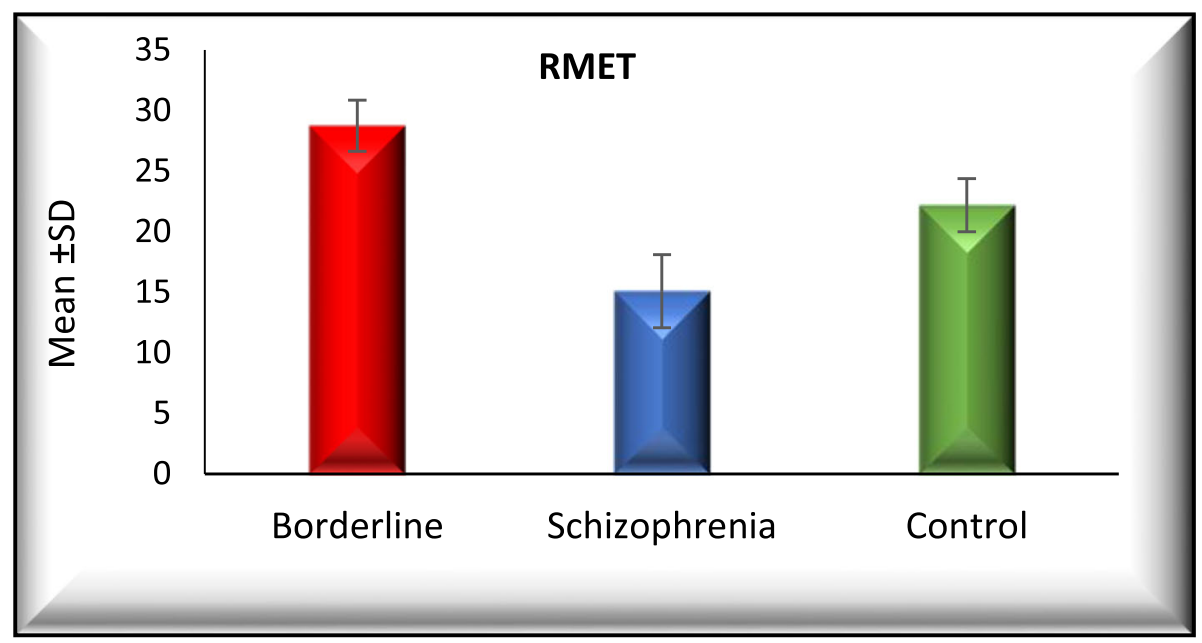

Fig. 1 Comparison of RMET mean score between the studied groups

\section{Discussion}

Social functioning impairment can be a clue to understand interpersonal problems associated with two of the most common mental illnesses namely, schizophrenia and BPD [23]. The interpersonal changes associated particularly with BPD involve affective, cognitive, behavioral, and disturbed relatedness symptoms, whereas negative symptoms of asociality, avolition, social withdrawal, and poor social skills are the characteristics of schizophrenia [4]. Interestingly, there is a strong evidence that ToM is considered a core concept in social functioning which can be used as a diagnostic criterion in these mental illnesses.

To our knowledge, there are inconsistent results regarding theory of mind (mentalization) processes, and what type of mentalization errors, occurs in patients with schizophrenia or BPD. Also, there is a lack of studies that linked ToM to suicidality in both BPD and schizophrenia.

This study aimed to assess affective ToM in BPD patients compared to schizophrenia patients and healthy controls and to identify the impact of ToM functioning and its clinical correlates to suicidal probability in the three groups.

Affective ToM was assessed by RMET as the most common measure for understanding how people process other's feelings and emotions [24, 25], and it was obvious that BPD had superiority in RMET score than control or schizophrenic patients $(P<.001)$, which means that BPD patients have enhanced affective theory of mind (hypermentalization). This has an agreement with findings of two similar studies [26, 27]. Another study has agreed with ours where BPD patients with and without the major depressive disorder (MDD) were found

Table 3 Comparison of suicide probability among the studied groups

\begin{tabular}{|c|c|c|c|c|c|c|c|c|c|c|c|}
\hline \multirow{3}{*}{$\begin{array}{l}\text { Variables } \\
\text { Hopelessness }\end{array}$} & \multirow[b]{3}{*}{ Range } & \multicolumn{6}{|c|}{ Groups } & \multirow{3}{*}{$\begin{array}{l}\text { ANOVA } \\
\boldsymbol{P} \text { value } \\
<0.001^{*}\end{array}$} & \multicolumn{3}{|c|}{ Tukey's test } \\
\hline & & \multicolumn{2}{|l|}{ BPD } & \multicolumn{2}{|c|}{ Schizophrenia } & \multicolumn{2}{|c|}{ Control } & & \multirow{2}{*}{$\begin{array}{l}\text { B\&S } \\
0.001^{*}\end{array}$} & \multirow{2}{*}{$\frac{\text { B\&C }}{<0.001^{*}}$} & \multirow{2}{*}{$\frac{S \& C}{0.003^{*}}$} \\
\hline & & 12 & 25 & 14 & 18 & 11 & 16 & & & & \\
\hline & Mean \pm SD & 19.95 & 3.395 & 15.75 & 1.209 & 13.35 & 1.348 & & & & \\
\hline \multirow[t]{2}{*}{ Suicidal ideation } & Range & 16 & 28 & 10 & 28 & 11 & 15 & $<0.001^{*}$ & $<0.001^{*}$ & $<0.001^{*}$ & $0.048^{*}$ \\
\hline & Mean \pm SD & 23.05 & 3.187 & 15.25 & 5.486 & 12.4 & 1.142 & & & & \\
\hline \multirow[t]{2}{*}{ Negative self-evaluation } & Range & 11 & 23 & 10 & 24 & 7 & 17 & $<0.001^{*}$ & $0.047^{*}$ & $<0.001^{*}$ & $0.011^{*}$ \\
\hline & Mean \pm SD & 17.15 & 3.014 & 14.55 & 3.927 & 11.35 & 3.117 & & & & \\
\hline \multirow[t]{2}{*}{ Hostility } & Range & 9 & 24 & 12 & 25 & 8 & 13 & $<0.001^{*}$ & $0.014^{*}$ & $<0.001^{*}$ & $<0.001^{*}$ \\
\hline & Mean \pm SD & 15.25 & 4.756 & 18.85 & 4.66 & 9.8 & 1.361 & & & & \\
\hline \multirow[t]{2}{*}{ Suicide probability score } & Range & 33 & 48 & 31 & 44 & 32 & 39 & $<0.001^{*}$ & $<0.001^{*}$ & $<0.001^{*}$ & $0.031^{*}$ \\
\hline & Mean \pm SD & 43.4 & 4.109 & 37.25 & 3.567 & 34.4 & 2.521 & & & & \\
\hline
\end{tabular}

$P$ value $>0.05$ : significant, * statistically significant, $S D$ standard deviation, $A N O V A$ analysis of variance, $B P D$ borderline personality disorder, $B$ borderline, $C$ controls, and $S$ schizophrenia 


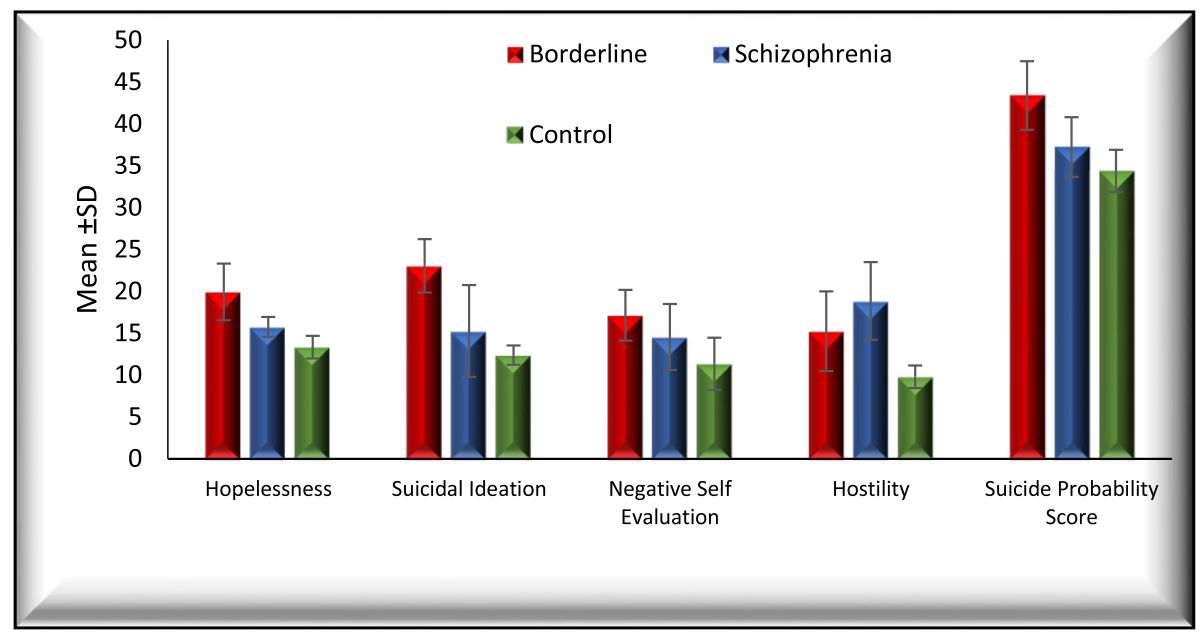

Fig. 2 Comparison of Suicide probability among the studied groups

scoring higher in affective ToM using RMET, particularly those without MDD [28]. This also supports earlier study findings that individuals with BPD are more accurate than healthy controls at detecting certain emotional states in facial emotion recognition tasks [29, 30].

Also, Normann-Eide and colleagues have agreed with our study results in that BPD patients were found to have a tendency to hypermentalize where ToM was investigated by the Movie for the Assessment of Social Cognition. Also, the study concluded that there was an association between hypermentalization and interpersonal problems in BPD patients and that they tend to misinterpret social information [31].

In line with our results, a study by Ortega-Díaz and colleagues has revealed that BPD patients have ToM deficits in the form of overmentalization when investigated by MASC and social functioning scale. Also, their firstdegree relatives showed significant differences in social functioning with regard to family relationships and interpersonal behavior compared to controls [14]. Consequently, according to all the mentioned studies BPD patients have increased sensitivity to the mental states

Table 4 Correlation between RMET and suicide probability in BPD group

\begin{tabular}{lll}
\hline Correlations & & \\
\hline BPD group & $\boldsymbol{R}$ & $\boldsymbol{P}$ value \\
\hline Hopelessness & 0.575 & $0.008^{*}$ \\
Suicidal ideation & 0.632 & $0.003^{*}$ \\
Negative self-evaluation & 0.236 & 0.316 \\
Hostility & 0.705 & $0.001^{*}$ \\
Suicide Probability Score & 0.826 & $<0.001^{*}$ \\
\hline
\end{tabular}

$P$ value $>0.05$ : significant, ${ }^{*}$ statistically significant, $B P D$ borderline personality disorder, RMET Reading the Mind in the Eye Test and social signals of others which may be an explanation for the social function difficulties.

Nevertheless, our results contradict other studies like a study by Levine et al. (1997) which found that individuals with BPD were less accurate at facial recognition tasks than healthy controls [32], a finding also supported in a later study by Bland and colleagues [13]. In addition, a study by Górska and Marszał revealed no difference in BPD patients and the control group in ToM level and the study relates such controversy of their results to a small sample size as well as the large intragroup differences particularly in education and age [8]. Similarly, the findings of an earlier study conducted by Preißler et al. did not report differences in mentalizing between BPD and healthy subjects [33]. However, in this study, some patients were medicated with psychotropic medications, which may have influenced the results.

Came in the same line, another study by Petersen and colleagues that have revealed the equal capability of both BPD and control groups in undertaking simple mentalization tasks, yet deficits in mentalization were detected in more complex tasks. The study

Table 5 Correlation between RMET and suicide probability in the schizophrenia group

\begin{tabular}{lll}
\hline Correlations & & \\
\hline Schizophrenia group & RMET & $\boldsymbol{P}$ value \\
\cline { 2 - 3 } & $\boldsymbol{R}$ & $0.017^{*}$ \\
\hline Hopelessness & -0.526 & 0.343 \\
Suicidal Ideation & -0.224 & 0.954 \\
Negative Self Evaluation & -0.014 & 0.575 \\
Hostility & -0.133 & 0.504 \\
Suicide Probability Score & -0.159 &
\end{tabular}

$P$ value $>0.05$ : significant, ${ }^{*}$ statistically significant, $R M E T$ Reading the Mind in the Eye Test 
showed significantly more mentalization errors on affective and cognitive understanding of faux pas and a Joke Appreciation task [34].

In schizophrenia, our study results have revealed a lower RMET score compared to both BPD patients and healthy controls indicating a deficit in ToM (hypomentalization) $(P<0.001)$. This goes with the results of GarcíaFernández and colleagues which compared the performance of 90 patients with schizophrenia in both first episode and chronic stage versus healthy controls using two ToM tasks (Hinting Task and RMET) and schizophrenia patients showed significantly poor performance than controls with more worsening in chronicity [35]. Another agreement came from a meta-analysis was conducted to answer a question regarding the possible impairment in ToM in schizophrenia and revealed a significant mentalization impairment in schizophrenia. Interestingly, patients in remission were also impaired which supports that mentalizing deficit is a core feature in schizophrenia, which agrees with the findings of our study [36].

Furthermore, by using another scale to assess ToM functioning as in a study done by Abdel-Hamid and her colleagues (2009) who used a computerized theory of mind (ToM) test consisting of a picture sequencing task and a questionnaire, ToM deficits existed in schizophrenia patients more frequently than controls [37]. Going through all of this research, we emphasize the fact that impairment in ToM is a stable trait feature in patients with schizophrenia.

In contrast, older studies that used another tool for ToM assessment compared patients with different symptom profiles or remitted to controls. Generally, it was concluded that deficits are only related to the severity of symptoms [38-40].

Suicide is a major psychiatric emergency, as the second leading cause of death in youth among adolescents and young adults [41].

In our study, BPD patients had superiority in suicide probability score than both patients with schizophrenia and healthy controls. Moreover, findings from the current study reveal that hypermentalization (enhanced affective ToM) detected in BPD patients shares a significant relation with suicidal probability. However, hypomentalization (less ToM) detected in schizophrenia had a nonsignificant relation with suicidal probability. This is in agreement with the findings of a study by Hatkevich and colleagues which revealed a significant relation between hypermentalization and suicide in adolescence [25].

In addition, several studies have suggested that individuals who engage in self-harm behaviors have significant hypermentalization errors that lead to difficulties with managing specific mental states and emotional dysregulation [42, 43]. Similarly, other findings proposed that these behaviors are coping strategies to alleviate negative effect resulting from hypermentalizing state [44].

To explain, Allen et al. (2008) named patients who have enhanced mental sensitivity to social signals by pseudo-mentalizing style, as they are overconcerned with the interpretation of information from others' mental states or emotions [45], which may be under affection by their own memories and personal beliefs [46]. Therefore, hypermentalizing is maladaptive for interpersonal functioning, as it may lead individuals to assume malevolent intentions of others and inappropriately respond (e.g., poor peer relations, misunderstanding of social interactions, severe rejection sensitivity, and loss of social support), all of which could underlie and exacerbate the emotion dysregulation [47-49].

So, Hatkevich et al.'s study has pointed out the importance of (1) early detection of patients with pseudohypermentalization tendency and (2) providing secondary prevention programs to adjust mentalizing style [25].

In contrast, Laghi et al.'s (2016) found mentalization skill deficits in patients with self-harm behaviors, compared to the controls. The differences between the studies' results could have been attributed to different tools used. Laghi et al. used the Theory of Mind Assessment Scale (TH.o.m.a.s), a semi-structured interview that assesses the subject's understanding of other's mental states in different situations [50].

Impairments in overall ToM especially the affective part are associated with suicidal probability. Therefore, psychotherapy programs which target mentalization skills hold promise for suicide risk identification, treatment, and prevention work.

Thus, current findings support results of previous treatment-based research, suggesting that interventions targeting social-cognitive processes and defects in mentalization as mentalization-based therapy (MBT) may be helpful in improving ToM impairments and associated suicide in BPD. For example, 3 previous RCT assessed the effects of MBT in BPD compared to standard clinical management. It was found that MBT was superior in terms of its effects on suicide attempts and self-harm. The experienced reduction in suicidality was sustained at the 5-year follow-up [51-53].

In schizophrenia, a significant high suicide probability existed compared to control $(P<<0.001)$. However, unfortunately, the correlation between RMET and suicidality assessed by SPS could not be proven with a significant difference in this study except for the hopelessness subdomain $(R=-0.526, P=0.017)$, though insignificant weak inverse relation existed between all suicide probability score domains and RMET. This is inconsistent with findings of the study by Canal-Rivero and colleagues conducted in 2019 to investigate the factors associated with multiple suicidal attempts in patients 
with the first episode of psychosis, and they found that patients with ToM deficit detected by false belief task (FBT) made more suicidal attempts than those without $(P=0.02)$. Moreover, errors in FBT were predictors of the number of suicides attempts in those patients $(B=0.48$, $t=2.11, P=0.04)$ [54]. Similarly, in an earlier study, ToM impairment was associated with suicidal behaviors in schizophrenia [55]. This finding also supported by a recent study revealed that social cognitive impairment is a predictor of suicidal behaviors in schizophrenic patients [56]. This controversy could owe to different tests used to investigate mentalization skills, different study designs, and criteria of the included participants.

Our study is limited by the small sample size, our sample is comprised of females only due to few numbers of males presented with BPD at our institute. So, our results cannot be generalized to whole BPD and schizophrenia patients. A second limitation is that not all domains of social cognition were assessed only affective ToM, as well we did not examine more complex mentalizing tasks to give more illustration of the magnitude and different patterns of social cognitive problems in BPD and schizophrenia. Therefore, further investigations are urged for further validation of the current evidence.

\section{Conclusions}

In summary, this comparative study aimed to differentiate between affective ToM deficit in borderline personality disorder and schizophrenia patients. The results revealed that hypermentalization in BPD patients was significantly correlated with a high probability of suicidality in those patients. While in schizophrenia, hypomentalization could not be linked to increased suicidality, though suicide probability in those patients was strongly exhibited more than control. Consequently, these results encourage the use of the RMET score to assess the affective theory of mind as a tool for early detection of suicidality in mental illnesses, particularly, BPD.

\section{Abbreviations \\ ANOVA: Analysis of variance; BPD: Borderline personality disorder; FH: Family history; MASC: Movie for the Assessment of Social Cognition; MDD: Major depressive disorder; RMET: Reading the Mind in the Eyes Test; SCID- I: Structured Clinical Interview for DSM-IV Axis I Disorders; SCID-II: Structured Clinical Interview for DSM-IV Axis II Disorders; SPS: Suicide Probability Scale; SPSS: Statistical Package for Social Science; ToM: Theory of mind}

\section{Acknowledgements}

Not applicable.

\section{Authors' contributions}

All authors had made a substantial contribution to the design of work, data collection and interpretation, writing the manuscript, revising it, and approving the final version. M.A. made the main effort in patient data collection. A.S, M.H, R.H, and Z.M made the major contribution in analyzing the results, reviewing current literature, and writing the manuscript. The authors read and approved the final manuscript.
Funding

The research was totally funded by the researchers.

\section{Availability of data and materials}

The dataset created and analyzed during the current study will be uploaded with the manuscript in Excel file format and will be available from the corresponding author on reasonable request.

\section{Declarations}

\section{Ethics approval and consent to participate}

The study conformed to the standards of the Ethical Review Committee, Ain Shams University (FMASU M D 339/2018). Before the study was inaugurated, a written informed consent was signed from study participants after adequately explaining the study aims and outcomes. The anonymity of the subjects was ensured, no identifying information was obtained, and the results were stored in a secure place with access only to the main author of the study.

\section{Consent for publication}

Not applicable.

\section{Competing interests}

The authors declare that they have no competing interests.

\section{Author details}

${ }^{1}$ Psychiatry Department, Psychological Medicine Hospital, Neuropsychiatry M.B.B.CH, Arab Board of Psychiatry, Cairo 11843, Egypt. ${ }^{2}$ Okasha institute of psychiatry, Faculty of medicine, Ain Shams University, Abbasiya, Cairo 1156, Egypt. ${ }^{3}$ Present Address: Okasha institute of psychiatry, Faculty of medicine, Ain Shams University, Abbasiya, Cairo 1156, Egypt.

Received: 26 July 2021 Accepted: 12 September 2021

Published online: 04 November 2021

\section{References}

1. Javed A, Charles A (2018) The importance of social cognition in improving functional outcomes in schizophrenia. Front Psychiatry 9:157. doi: https:// doi.org/10.3389/fpsyt.2018.00157. 2016.09.019.

2. Tremblay S, Sharika KM, Platt ML (2017) Social decision-making and the brain: A comparative perspective. Trends Cogn Sci 21(4):265-276. https:// doi.org/10.1016/j.tics.2017.01.007

3. Dore RA, Amendum SJ, Golinkoff RM, Hirsh-Pasek K (2018) Theory of Mind: a Hidden Factor in Reading Comprehension? Educ Psychol Rev 30(3):10671089. https://doi.org/10.1007/s10648-018-9443-9

4. Martins-Junior FE, Sanvicente-Vieira B, Grassi-Oliveira R, Brietzke E (2011) Social cognition and theory of mind: controversies and promises for understanding major psychiatric disorders. Psychol Neurosci 4:347-351. https://doi.org/10.3922/j.psns.2011.3.008

5. Ten Have M, Verheul R, Kaasenbrood A, van Dorsselaer S, Tuithof M, Kleinjan M, de Graaf R (2016) Prevalence rates of borderline personality disorder symptoms: a study based on the Netherlands Mental Health Survey and Incidence Study-2. BMC Psychiatry 16(1):249. https://doi.org/10.1186/s12888016-0939-x

6. Fonagy P, Luyten P (2009) A developmental, mentalization-based approach to the understanding and treatment of borderline personality disorder. Dev Psychopathol 21(4):1355-1381. doi: https://doi.org/10.1017/S09545794 09990198.

7. Guilé JM, Boissel L, Alaux-Cantin S, de La Rivière SG (2018) Borderline personality disorder in adolescents: prevalence, diagnosis, and treatment strategies. Adolesc Health Med Therapeutics 9:199-210. https://doi.org/1 $0.2147 /$ AHMT.S156565

8. Górska D, Marszał M (2014) Mentalization and theory of mind in borderline personality organization: exploring the differences between affective and cognitive aspects of social cognition in emotional pathology. Psychiatr Pol 48(3):503-513

9. Patel KR, Cherian J, Gohil K, Atkinson D (2014) Schizophrenia: overview and treatment options. Pharmacy Therapeutics 39(9):638-645

10. Richetin J, Preti E, Costantini G, De Panfilis C (2017) The centrality of affective instability and identity in borderline personality disorder: evidence 
from network analysis. PLoS One 12(10):e0186695. https://doi.org/10.1371/ journal.pone.0186695

11. Stanley B, Siever $\sqcup J$ (2010) The interpersonal dimension of borderline personality disorder: toward a neuropeptide model. Am J Psychiatry 167(1): 24-39. https://doi.org/10.1176/appi.ajp.2009.0905074

12. Bateman AW, Fonagy P (2003) The development of an attachment-based treatment program for borderline personality disorder. Bull Menn Clin 67(3): 187-211. https://doi.org/10.1521/bumc.67.3.187.23439

13. Bland AR, Williams CA, Scharer K, Manning S (2004) Emotion processing in borderline personality disorders. Issues Mental Health Nurs 25(7):655-672. https://doi.org/10.1080/01612840490486692

14. Ortega-Díaz E, García-Campos J, Moya-Martínez A, Ramírez-Cremades C, Rico-Gomis JM, Cuesta-Moreno C, Palazón-Bru A, Estan-Cerezo G, Piqueras JA, Rodríguez-Marín J (2021) Theory of mind in borderline personality disorder: a possible endophenotypic factor? Int J Environ Res Public Health 18(6):3193. https://doi.org/10.3390/ijerph18063193

15. First MB, Spitzer RL, Williams w, et al. (1996) Structured clinical interview for DSM-IV Axis I disorders (SCID I) in handbook of psychiatry measures. American Psychiatric Association, Washington, DC

16. El Missiry A, Sorour A, Sadek A, Fahy T, AbdelMawgoud M, Asaad T (2004) Homicide and psychiatric illness: an Egyptian study (MD Thesis). Faculty of Medicine, Ain Shams University, Cairo

17. First MB, Gibbon M, Spitzer RL, Williams JBW, Benjamin LS (1997) Structured clinical interview for DSM-IV axis II personality disorders, (SCID-II). American Psychiatric Association, Washington, DC

18. Hattata H, ASaad T, Abo Zied M (2004) dual diagnosis in substance use disorders. M.D. degree thesis, Faculty of Medicine, Ain Shams University.

19. Baron-Cohen S, Wheelwright S (2001) The "Reading the Mind in the Eyes" Test revised version: a study with normal adults, and adults with Asperger syndrome or high-functioning autism. J Child Psychol Psychiatry 42(2):241251. https://doi.org/10.1017/\$0021963001006643

20. Gohar SM, EmadHamdi LA, El Ray (2013) Adapting and evaluating a social cognitive remediation program for schizophrenia in Arabic. Schizophr Res 148(1-3):12-17. https://doi.org/10.1016/j.schres.2013.05.008

21. Cull JG, Gill WS (1982) Suicide Probability Scale. Western Psychological Services, Los Angeles, CA

22. Albehairy AA (2013) Manual of suicidality probability scale Arabic version the third edition published by Alanglo Almasreya Library, Cairo, Egypt, pp 1-8

23. Vaskinn A, Antonsen BT, Fretland RA, Dziobek I, Sundet K, Wilberg T (2015) Theory of mind in women with borderline personality disorder or schizophrenia: differences in overall ability and error patterns. Front Psychol 6. doi: https://doi.org/10.3389/fpsyg.2015.01239.

24. Dietze P, Knowles ED (2021) Social class predicts emotion perception and perspective-taking performance in adults. Personal Soc Psychol Bull 47(1): 42-56. https://doi.org/10.1177/0146167220914116

25. Hatkevich C, Venta A, Sharp C (2019) Theory of mind and suicide ideation and attempt in adolescent inpatients. J Affect Disord 256:17-25. doi: https:// doi.org/10.1016/j.jad.2019.05.051.

26. Fertuck EA, Jekal A, Song I, Wyman B, Morris MC, Wilson ST, Brodsky BS, Stanley B (2009) Enhanced 'Reading the Mind in the Eyes' in borderline personality disorder compared to healthy controls. Psychol Med 39(12): 1979-1988. https://doi.org/10.1017/S003329170900600X

27. Frick C, Lang S, Kotchoubey B, Sieswerda S, Dinu-Biringer R, Berger M, Veser S, Essig M, Barnow S. (2012) Hypersensitivity in borderline personality disorder during mindreading. PLoS One 7(8):e41650. doi: https://doi.org/1 0.1371/journal.pone.0041650.

28. Zabihzadeh A, Maleki G, Richman MJ, Hatami AJ, Alimardani Z, Heidari M (2017) Affective and cognitive theory of mind in borderline personality disorder: the role of comorbid depression. Psychiatry Res 257:144-149. https://doi.org/10.1016/.jpsychres.2017.07.034

29. Wagner AW, Linehan MM (1999) Facial expression recognition ability among women with borderline personality disorder: implications for emotion regulation. J Personal Disord 13(4):329-344. https://doi.org/10.1 521/pedi.1999.13.4.329

30. Lynch TR, Rosenthal MZ, Kosson DS, Cheaven JS, Lejuez CW, Blair RJR (2006) Heightened sensitivity to facial expressions of emotion in borderline personality disorder. Emotion 6(4):647-655. https://doi.org/10.1037/1528-3 542.6.4.647

31. Normann-Eide E, Antonsen BRT, Kvarstein EH, Pedersen G, Vaskinn A, Wilberg T (2020) Are impairments in theory of mind specific to borderline personality disorder? J Personal Disord 34(6):827-841. https://doi.org/10.1 521/pedi_2019_33_417

32. Levine D, Marziali E, Hood J (1997) Emotion processing in borderline personality disorders. J Nerv Ment Dis 185(4):240-246. https://doi.org/10.1 097/00005053-199704000-00004

33. Preißler S, Dziobek I, Ritter K, Heekeren HR, Roepke S (2010) Social cognition in borderline personality disorder: evidence for disturbed recognition of the emotions, thoughts, and intentions of others. Front Behav Neurosci 4:182. https://doi.org/10.3389/fnbeh.2010.00182

34. Petersen $R$, Brakoulias V, Langdon R (2016) An experimental investigation of mentalization ability in borderline personality disorder. Compr Psychiatry 64: 12-21. doi: https://doi.org/10.1016/j.comppsych.2015.10.004.

35. García-Fernández L, Cabot-Ivorra N, Romero-Ferreiro V, Pérez-Martín J, Rodriguez-Jimenez R (2020) Differences in theory of mind between early and chronic stages in schizophrenia. J Psychiatr Res 127:35-41. https://doi. org/10.1016/j.jpsychires.2020.05

36. Sprong M, Schothorst P, Vos E, Hox J, Van Engeland H (2007) Theory of mind in schizophrenia: meta-analysis. Br J Psychiatry 191(1):5-13. https://doi. org/10.1192/bjp.bp.107.035899

37. Abdel-Hamid M, Lehmkämper C, Sonntag C, Juckel G, Daum I, Brüne M (2009) Theory of mind in schizophrenia: the role of clinical symptomatology and neurocognition in understanding other people's thoughts and intentions. Psychiatry Res 165(1-2):19-26. https://doi.org/10.1016/j.psychres.2 007.10 .021

38. Drury VM, Robinson EJ, Birchwood M (1998) 'Theory of mind' skills during an acute episode of psychosis and following recovery. Psychol Med 28(5): 1101-1112. https://doi.org/10.1017/\$0033291798006850

39. Sarfati Y, Hardy-Baylé MC (1999) How do people with schizophrenia explain the behaviour of others? A study of theory of mind and its relationship to thought and speech disorganization in schizophrenia. Psychol Med 29(3): 613-620. https://doi.org/10.1017/S0033291799008326

40. Pickup G, Frith CD (2001) Theory of mind impairments in schizophrenia: symptomatology, severity, and specificity. Psychol Med 31(2):207-220. https://doi.org/10.1017/S0033291701003385

41. Burstein B, Agostino H, Greenfield B (2019) Suicidal attempts and ideation among children and adolescents in US emergency departments, 2007-2015. JAMA Pediatr 173(6):598-600. https://doi.org/10.1001/jamapediatrics.2019.0464

42. Klonsky ED (2007) The functions of deliberate self-injury: a review of the evidence. Clin Psychol Rev 27(2):226-239. https://doi.org/10.1016/j.cpr.2006. 08.002

43. Klonsky ED, May AM, Glenn CR (2013) The relationship between non suicidal self-injury and attempted suicide: converging evidence from four samples. J Abnorm Psychol 122(1):231-237. https://doi.org/10.1037/a0030278

44. Di Pierro R, Sarno I, Gallucci M, Madeddu F (2014) Nonsuicidal self-injury as an affect-regulation strategy and the moderating role of impulsivity. Child Adolesc Mental Health, 19(4), 259-264. doi: https://doi.org/10.1111/camh.12063.

45. Allen, J.G., Fonagy, P., Bateman, A.W., 2008. Mentalizing in clinical practice. American Psychiatric Publishing, Inc.

46. Sharp C, Pane H, Ha C, Venta A, Patel AB, Sturek J, Fonagy P (2011) Theory of mind and emotion regulation difficulties in adolescents with borderline traits. J Am Acad Child Adolesc Psychiatry 50 (6) 563 - 573. doi: https://doi. org/10.1016/j.jaac.2011.01.017.

47. Kalpakci A, Vanwoerden S, Elhai J, Sharp C (2016) The independent contributions of emotion dysregulation and hypermentalization to the "double dissociation" of affective and cognitive empathy in female adolescent inpatients with BPD. J Personal Disord 30(2):242-260. https://doi. org/10.1521/pedi_2015_29_192

48. Sharp C (2014) The social-cognitive basis of BPD: a theory of hypermentalizing. In: Handbook of Borderline Personality Disorder in Children and Adolescents. Springer, New York, pp 211-225. https:/doi.org/1 0.1007/978-1-4939-0591-1_15

49. Sharp C, Vanwoerden S (2015) Hypermentalizing in borderline personality disorder: a model and data. J Infant Child Adolesc Psychother 14(1):33-45. https://doi.org/10.1080/15289168.2015.1004890

50. Laghi F, Terrinoni A, Cerutti R, Fantini F, Galosi S, Ferrara M, Bosco FM (2016) Theory of mind in non-suicidal self-injury (NSSI) adolescents. Conscious Cogn 43, 38-47. doi: https://doi.org/10.1016/j.concog.2016.05.004.

51. Bateman A, Fonagy P (2008) 8-year follow-up of patients treated for borderline personality disorder: mentalization-based treatment versus treatment as usual. Am J Psychiatry 165(5):631-638. https://doi.org/10.11 76/appi.ajp.2007.07040636 
52. Bateman A, Fonagy P (2009) Randomized controlled trial of outpatient mentalization-based treatment versus structured clinical management for borderline personality disorder. Am J Psychiatr 166(12):1355-1364. doi: https://doi.org/10.1176/foc.8.1.foc55

53. Juul S, Lunn S, Poulsen S, Sørensen P, Salimi M, Jakobsen JC, Bateman A, Simonsen S (2019) Short-term versus long-term mentalization based therapy for outpatients with subthreshold or diagnosed borderline personality disorder: a protocol for a randomized clinical trial. Trials 20(1): 196. https://doi.org/10.1186/s13063-019-3306-7

54. Canal-Riveroa M, Velasco-Barbanchob E, Barrigonc ML, Villar-Cabezad F, Obiols-Llandriche JE, Crespo-Facorro B, Ruiz-Veguilla M (2019) Personality traits, theory of mind and their relationship with multiple suicide attempts in a sample of first episode psychosis patients: one-year follow-up study. J Affect Disord 256:176-182. https://doi.org/10.1016/j.jad.2019.05.078

55. Canal-Rivero L-MJD, Barrigon ML, Perona-Garcelan S, JimenezCasado C, David AS, Obiols-Llandrich JE, Ruiz-Veguilla M (2017) The role of premorbid personality and social cognition in suicidal behaviour in first-episode psychosis: a one-year follow-up study. Psychiatry Res 256:13-20. https://doi. org/10.1016/j.psychres.2017.05.050

56. Depp CA, Villa J, Schembari BC, Harvey PD, Pinkham A (2018) Social cognition and short-term prediction of suicidal ideation in schizophrenia. Psychiatry Res 270:13-19. https://doi.org/10.1016/J.PSYCHRES.2018.09.005

\section{Publisher's Note}

Springer Nature remains neutral with regard to jurisdictional claims in published maps and institutional affiliations.

\section{Submit your manuscript to a SpringerOpen ${ }^{\circ}$ journal and benefit from:}

- Convenient online submission

- Rigorous peer review

- Open access: articles freely available online

- High visibility within the field

- Retaining the copyright to your article

Submit your next manuscript at $\boldsymbol{\nabla}$ springeropen.com 